\title{
Review
}

\section{Growing burden of noncommunicable diseases: the contributory role of oral diseases, Eastern Mediterranean Region perspective}

\author{
S.A.H. Bokhari ${ }^{1}$ and A.A. Khan ${ }^{1}$
}

$$
\begin{aligned}
& \text { العبء المتزايد للأمر اض غير السارية: الدور المسهم لأمر اض الفم فيه، منظور إقليم شرق المتوسط }
\end{aligned}
$$

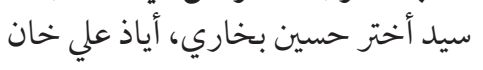

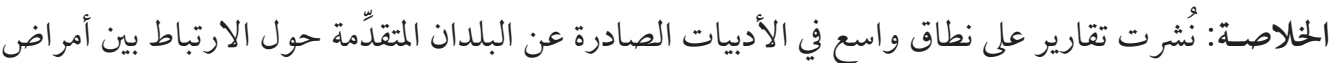

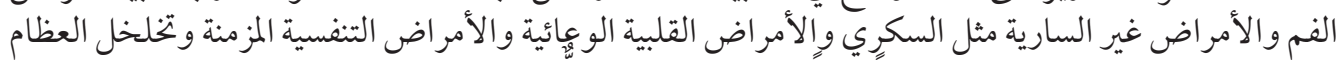

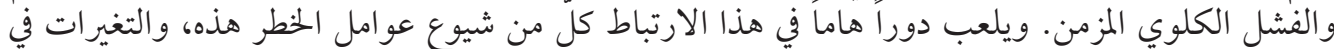

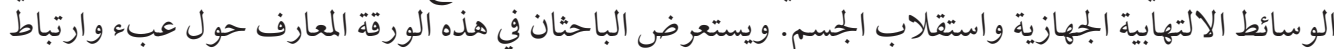

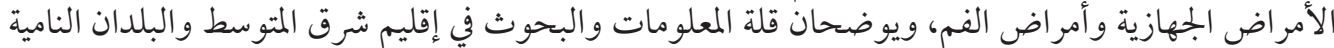

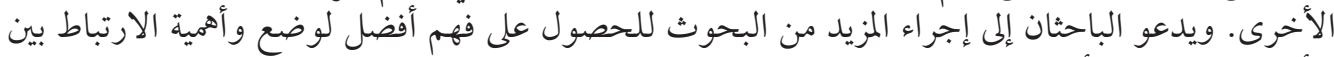

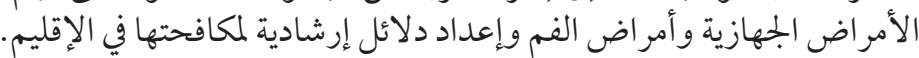

ABSTRACT Associations of oral diseases with noncommunicable diseases such as diabetes, cardiovascular diseases, chronic respiratory diseases, osteoporosis and chronic renal failure are widely reported in the literature from developed countries. Commonality of risk factors, changes in systemic inflammatory mediators and body metabolism play a role in this association. This paper reviews current knowledge on the burden and association of oral and systemic diseases, and highlights the paucity of information and research from the Eastern Mediterranean Region and other developing countries. A call is made for further research to understand the status and significance of oral-systemic disease associations and develop guidelines for their control in this Region.

\begin{abstract}
Charge croissante des maladies non transmissibles : le rôle contributif des affections buccodentaires. Le point de vue de la Région de la Méditerranée orientale

RÉSUMÉ L'association entre les atteintes bucco-dentaires et les maladies non transmissibles telles que le diabète, les maladies cardiovasculaires, les maladies respiratoires chroniques, l'ostéoporose et l'insuffisance rénale chronique fait l'objet d'une abondante littérature dans les pays développés. Les points communs entre les facteurs de risque, les modifications au niveau systémique des médiateurs inflammatoires et le métabolisme du corps humain jouent un rôle dans cette association. Cet article examine les connaissances actuelles sur la charge des maladies bucco-dentaires et systémiques et leur association, et met en lumière le manque d'information et de recherche dans la Région de la Méditerranée orientale et les autres pays en développement. Un appel à l'intensification de la recherche est lancé, afin que l'on comprenne l'importance et la signification de l'association entre maladies buccodentaires et systémiques et que l'on définisse des lignes directrices permettant de lutter contre ces maladies dans la Région.
\end{abstract}

${ }^{1}$ Department of Oral Health Sciences, Sheikh Zayed Federal Postgraduate Medical Institute, Lahore, Pakistan (Correspondence to S.A.H. Bokhari: pdplhr@yahoo.com).

Received: 14/08/06; accepted: 18/01/07

المجلة الصحية لشرق المتوسط، منظمة الصحة العالمية، المجلد الخامس عشر، العدد ع، 9 +. 


\section{Introduction}

The world is facing an epidemic of chronic diseases, especially noncommunicable diseases (NCD). Heart disease, stroke, cancer, diabetes and chronic respiratory disease are the leading causes of death in every region of the world [1]. In countries of the Eastern Mediterranean Region (EMR) $47 \%$ of the Region's burden of disease is currently due to $\mathrm{NCD}$, and this is expected to rise to $60 \%$ by the year 2020 [2]. It is predicted that by 2020 these diseases will be causing 7 out of every 10 deaths in developing countries [3] and $60 \%$ of all mortality will be attributable to NCD [4]. Future decades will see dramatic changes in the health needs of poor and developing countries. In view of the estimates of the growing burden of NCD on the lives of poor people, greater recognition of the importance of NCD is needed [5].

Oral diseases are included among the World Health Organization (WHO) definition of chronic diseases [1], and the importance of oral health is recognized as more than just healthy teeth: "the mouth is a mirror of health or disease, a sentinel or early warning system, an accessible model for the study of other tissues and organs and as a potential source of pathology affecting other systems and organs" [6].

Oral-systemic disease connections are not new and according to the American Dental Association as many as 200 possible associations between systemic conditions and oral manifestations can be identified in the literature [7]. The relationship of poor oral health - mainly due to periodontal diseases and/or tooth loss - and increased risk of cardiovascular diseases (CVD), pulmonary diseases, diabetes, pregnancy outcomes, and all-cause mortality have become a constant issue of discussion in the current scientific literature [8]. These chronic systemic and oral diseases share many common risk fac- tors such as heredity, age, sex, education, sedentary lifestyle, smoking, diet and obesity [9]. Epidemiological and clinical studies identify a relationship between oral diseases and NCD, but the relationship has not been clearly established as a causal one. Several pathophysiological pathways of association are postulated to explain this relationship. Certain criteria for a cause-effect relationship have been suggested which provide a direction for future investigations.

The objective of this review article was to explore the literature for information on the status, association and burden of oral diseases in relation to NCD in developing countries generally and the EMR especially in order to review the body of global research evidence about possible pathways of infection. The rationale of this review was to highlight the lack of information and research about the impact of oral diseases on NCD in this Region and to stress the importance of oral health issues in medicine in relation to the risk of NCD.

\section{Research method}

Online searches were made to find literature on oral diseases, e.g. dental caries, periodontal diseases and tooth loss, and on NCD, e.g. CVD, diabetes, chronic respiratory diseases, osteoporosis and renal complications. PubMed and websites of peer-reviewed journals, WHO, World Heart Federation, International Diabetes Federation and other health organizations were browsed to collect the required information related to NCD and oral diseases.

\section{Burden of oral diseases}

Oral diseases are prevalent globally. Dental caries and periodontal diseases, which have historically been considered the most im- 
portant global oral health burdens, vary in distribution and severity in different parts of the world [10]. The prevalence and severity of oral diseases is affected by age, sex, race, geographic area, socioeconomic factors, local and systemic factors and methods of oral cleansing [11].

Dental caries affect $60 \%-90 \%$ of schoolchildren and adults in EMR countries. The average decayed/missing/filled teeth (DMF) score exceeds 2.00. The problem of missing teeth is reported to be smaller in industrialized countries than in developing countries. Edentulism in those aged $65+$ years is reported as 7\% for Egypt, 20\% for Lebanon and $31 \%-46 \%$ for Saudi Arabia [12]. While there is research on missing teeth in EMR countries, e.g. from Jordan [13], in general data from the Region are sparse. Periodontal disease is prevalent in all age groups; the current view is that some $5 \%-20 \%$ of any population suffers from severe generalized periodontitis, and moderate disease affects a majority of adults. If the minimum level of disease is defined as "one site of clinical loss of attachment of $2 \mathrm{~mm}$ or more", around $80 \%$ of all adults and over $90 \%$ of those aged 55-64 years are affected [14]. WHO data confirm that the problem of dental caries continues to increase and that the prevalence of periodontal disease remains high in developing countries [15].

\section{Oral disease and diabetes}

A bidirectional relationship of diabetes and periodontal diseases is reported in the literature [16,17], as the presence of one condition tends to promote the other and periodontal disease is graded as the 6th most common complication of diabetes mellitus [18]. Greater prevalence, severity, extent or progression of periodontal diseases [19], greater tooth loss when compared with general populations $[18,20]$, higher incidence of dental caries [21] and poor oral health [20] are reported in diabetic patients. However there is insufficient evidence to determine a relationship between diabetes and higher risk for coronal or root caries [17].

The relationship between diabetes mellitus and periodontal disease has been explained in many ways. Oral infections serve as metabolic stressors that may exacerbate systemic disease [21] and bacterial products propagate an inflammatory response in the host through Toll-like receptors that induce an inflammatory cascade [22]. The physiological phenomena of impaired body resistance, vascular changes, altered oral microflora and abnormal collagen metabolism found in diabetes may explain the association with periodontitis [23].

\section{Oral disease and cardiovascular disease}

Oral infections are associated with CVD as risk factors and this association is independent of the "classic" coronary risk factors [24]. One review of studies and several cross-sectional, case-control and follow-up studies report a positive association of poor oral health with CVD [12,25-29]. These include an association of periodontitis with carotid calcification and stroke [26]; of tooth loss and periodontal parameters (periodontal pocket and clinical attachment loss) with cases of myocardial infarction and angina [27]; and of chronic periodontitis with future events of acute myocardial infarction [28]. But the associations of other oral health indicators, e.g. dental caries, presence of remaining teeth, dental plaque and dentures, with CHD deaths are not significant [29].

The association between poor oral health and CHD is explained by changes in inflammatory and haemostatic factors [30]. Key inflammatory mediators [C-

المجلة الصحية لشرق المتوسط، منظمة الصحة العالمية، المجلد الخنامس عشر، العدد ع، 9 +. 
reactive protein (CRP), serum amyloid A, ceruloplasmin, alpha(1)-acid-glycoprotein and alpha(1)-antichymotrypsin] increased 3 -fold in patients with both CVD and periodontal disease [31]; CRP increases independently in patients with periodontitis [32] and coronary calcification [33] and is associated with increased risk for future development of atherosclerosis in periodontitis patients [34]. White blood cell counts increased with the severity of periodontitis in both smoking and nonsmoking groups of patients [35]. Concentrations of pro-inflammatory markers (interleukin-1 $\beta$, tumour necrosis factor- $\alpha$, interleukin-2, interferon cytokine-y) were on average significantly higher in serum samples and gingival tissue biopsies from periodontitis patients than healthy controls [36]. Lipid profiles also showed that total cholesterol/ high-density lipoprotein cholesterol ratio was higher in patients with periodontitis and CVD [37].

Intervention studies have shown an influence of periodontal treatment in CVD patients by bringing changes in serum inflammatory and haemostatic markers, suggesting that prevention and control of periodontal diseases may play a role in the initiation and/or progression of CVD [34,38-40]. CRP levels were modified by periodontal treatment [41].

\section{Oral disease and chronic respiratory disease}

Recent studies provide evidence that oral infections may influence the initiation and progression of lung disease, but the link remains controversial $[42,43]$. Joshipura has reported a high prevalence of dental plaque colonization of potential pathogens for bacterial pneumonia, an association of anaerobic pulmonary infection with periodontitis, an association of poor oral hygiene with chronic respiratory disease, an association of alveolar bone loss at baseline with subsequent pulmonary disease and systemic activation of cytokines in periodontal disease [8]. Meta-analysis of 5 intervention studies on the relationship of oral hygiene and pneumonia showed that improvement in oral hygiene reduced incidence of nosocomial pneumonia by on average $40 \%$ [44].

\section{Oral disease and osteoporosis}

The literature provides increasing evidence that osteoporosis is associated with periodontitis and tooth loss [45], but the results are inconsistent. Reviews of studies demonstrate a significant association between bone mass density of the mandible and peripheral skeleton, and a correlation between decreased mandibular bone mass and tooth loss [46,47], but this is not definitely proven. Bollen et al. reported an association of osteoporotic fractures with the number of teeth and with age [48]. Klemetti suggested that individuals with high mineral values in the skeleton seem to retain their teeth with deep periodontal pockets more easily than those with osteoporosis [49]. A casecontrol study found no statistically significant differences between osteoporotic patients for cortical width, panoramic mandibular index, alveolar crest resorption degree, fractal dimension and the number of mandibular teeth, but there was a difference for cortical index [47].

Studies report that there is an association between edentulousness, periodontal disease and longitudinal changes in mandibular bone mass density [50]; that the present number of teeth are highly related to thoracic spine fracture and with latent osteoporosis [51]; and that a decrease in mandibular bone mass positively correlates with tooth loss in females, but not in males [52]. 


\section{Oral diseases and chronic renal failure}

Data on the epidemiology of chronic renal failure (CRF) are available for many European countries, but limited for other countries. Oral soft and hard tissues are significantly affected as result of CRF. Children with CRF have significantly fewer dental caries than healthy children due to the inhibitory effect of increased salivary urea levels, and an early effect of enamel hypoplasia is due to a defect of enamel development and mineralization [16,53]. As reported in many epidemiological and case-control studies CRF is associated with several oral manifestations, e.g. with oral infections, dental anomalies of delayed eruption and enamel hypoplasia in children and gingival enlargement in adults $[16,54]$ and with poor oral hygiene and significantly higher plaque and calculus indices [55]. An increased risk of periodontitis has been reported in $80.6 \%$ of haemodialysis cases [56], and premature tooth loss and localized suppurative osteomyelitis secondary to periodontitis in individuals receiving haemodialysis. CRF has also been associated with symptoms of xerostomia and reduced salivary flow $[57,58]$; oral uraemic malodour/bad taste [59]; and petechia and/ or ecchymosis and increased tongue coating and mucosal lesions such as uraemic stomatitis [60].

\section{Possible pathways of association between oral disease and NCD}

Many pathways of association of oral infections and NCD have been postulated, e.g:

- Oral infections might contribute to the pathogenesis of CHD by the effects of endotoxins on the circulation; the role of heat-shock proteins; infection-induced perturbations in lipid profiles; and the formation of acute-phase reactants [61].

- Aspiration of saliva contaminated with oral bacteria, endotoxins, lipopolysaccharides and enzymes promotes inflammation and infection of the lower respiratory tract and may develop to chronic obstructive pulmonary disease [62].

- Osteoporosis affects alveolar bone density that contributes towards a progression of periodontitis [63] that results in a weakening of the tooth socket and eventual loss of teeth [64].

- In diabetes the association with oral disease includes microvascular changes; changes in the components of the gingival crevicular fluid; changes in collagen metabolism; an altered host response; alteration in subgingival flora; genetic predisposition; and monoenzymatic glycation [65].

- In renal failure, oral infections correlate with markers of malnutrition and inflammation [66]; immunosuppression with cyclosporine A; reduced immunodeficiency [53]; and use of antihypertensive calcium-blocking agents [56].

\section{Discussion}

A great volume of research is available in the literature about the association of oral disease with NCD such as diabetes or CVD. The global health challenge posed by the escalating burden of NCD in the developing world is well documented in various reports and publications [67]. Chronic diseases are a larger problem in low-income settings. Data on the global burden of NCD reveals a clear dominance of CVD, and research on chronic diseases in resource-poor nations remains embryonic [68]. A permanent threat of systemic toxicity and injury may be anticipated

المجلة الصحية لشرق المتو سط، منظمة الصحة العالمية، المجلد الخامس عشر، العدد ع، 9 +. 
through bacterial endotoxins from oral origin entering the bloodstream, especially in patients with severe periodontal disease [69]. The emerging concept of "periodontal medicine" highlights the importance of research into periodontal-systemic relationships as a major source of potential contributory risk factors for systemic diseases [70]. Research on oral diseases is neglected and has a small share in the medical research work of developing countries. A stark illustration of the divide between the developed and developing world is provided by expenditure on global health research. Of the US $\$ 70$ billion spent annually, only $10 \%$ is allocated to poor countries that bear $90 \%$ of the world's disease burden: the so-called "10-90 gap" [71].

Poor literacy rates and lack of awareness of disease symptoms in the population of developing nations results in worse disease outcomes [72]. People of South Asian descent have one of the highest risks of CVD in the world. Thus it is likely that escalation of the global CVD epidemic will be most marked in Pakistan and India [73], and available data from the EMR shows that both men and women are at high risk [3]. Urbanization and industrialization bring changes in lifestyle that can affect oral and general health. Although oral health problems appear not to be life-threatening and have a low burden on daily life, when it comes to quality of life, oral and dental conditions are characterized in terms of "impairment, disability and handicap" [12]. Like other NCDs, oral diseases such as periodontal diseases, dental caries and tooth loss are preventable and controllable through healthy behaviours and lifestyle changes. Prevention is the most effective way of combating CVD and other chronic diseases [73].

Abundant information about these challenging diseases and guidelines for preven- tion and control are available for developed countries, while there is poor representation of research and literature from developing countries that have the greatest disease burden [71]. The volume of research and production of scientific knowledge in developing countries is negligible. Dental scientific literature productivity in EMR countries is estimated to be $2.46 \%$ of the total scientific literature [74].

\section{Conclusion}

The literature provides evidence for an association with and contributory role of oral diseases to NCD, working through systemic pathophysiological phenomena. Understanding the association of tooth loss, periodontal disease and other oral health parameters with NCD remains uncertain until prospective controlled studies are conducted. The studies available are largely from developed countries and few report any research on oral-systemic disease relationships from the EMR. The wide gap of representation of health issues between developed and developing countries needs to be addressed. This calls for attention from the WHO, World Bank and other international research organizations to address the issue in developing countries where NCD are becoming more of a challenge. There is a need to include oral diseases in WHO's STEPwise approach of disease surveillance while doing research on the prevention and control of NCD in countries at high risk of NCD and where relevant data on oral diseases is scarce [75]. It is important to establish a system of global surveillance of diseases based on the principles of equality of all people and health improvement as a common goal of humanity [76]. 


\section{References}

1. Preventing chronic diseases: a vital investment. WHO global report. Geneva, World Health Organization, 2005.

2. Khatib O. Noncommunicable diseases: risk factors and regional strategies for prevention and care. Eastern Mediterranean health journal, 2004, 10(6):778-88.

3. Boutayeb A, Boutayeb S. The burden of non communicable diseases in developing countries. International journal for equity in health, 2005, 4:2

4. Puska P. Nutrition and global prevention on non-communicable diseases. Asia Pacific journal of clinical nutrition, 2002 , 11(Suppl. 9):S755-8.

5. Murray C, Lopez A. Progress and directions in refining the global burden of disease: a response to Williams. Health economics, 2000, 9:69-82.

6. Oral health in America: a report of the surgeon general. Executive summary. Rockville, Maryland, National Institute of Dental and Craniofacial Research, 2000.

7. Bricker SL, Langlais RP, Miller CS, eds. Oral diagnosis, oral medicine and treatment planning. Philadelphia, Lea and Febiger, 1994.

8. Joshipura KD, Ritchie C, Douglass C. Strength of evidence linking oral conditions and systemic disease. Compendium of continuing education in dentistry 2000, 21(Suppl. 30):13-23.

9. Page RC. The pathology of periodontal diseases may affect systemic diseases: inversion of a paradigm. Annals of periodontology, 1998, 3(1):108-20.

10. Petersen PE et al. The global burden of oral diseases and risks to oral health. Bulletin of the World Health Organization, 2005, 83:661-9.

11. Epidemiology, etiology, and prevention of periodontal diseases. Geneva, World
Health Organization, 1978 (Technical Report Series, No. 621).

12. WHO oral health country/area profile 2003. Geneva, World Health Organization, 2003 (http://www.whocollab.od.mah.se/index. html, accessed 9 October 2008).

13. Hamasha AH, Sasa I, Al Qudah M. Risk indicators associated with tooth loss in Jordanian adults. Community dentistry and oral epidemiology, 2000, 28:67-72.

14. Position paper: epidemiology of periodontal diseases. American Academy of Periodontology. Journal of periodontology, 1996, 67:935-45.

15. Beiruti N. Views on oral health care strategies. Eastern Mediterranean health journal, 2005, 11(1/2):209-16.

16. Taylor GW, Manz MC, Borgnakke WS. Diabetes, periodontal diseases, dental caries, and tooth loss: a review of the literature. Compendium of continuing education in dentistry, 2004, 25(3):179-84.

17. Grossi SG, Genco RJ. Periodontal disease and diabetes mellitus: a two-way relationship. Annals of periodontology, 1998, 3(1):51-61.

18. Mattson JS, Cerutis DR. Diabetes mellitus: a review of the literature and dental implications. Compendium of continuing education in dentistry, 2001, 22(9):75760.

19. Taylor GW. Bidirectional interrelationships between diabetes and periodontal diseases: an epidemiologic perspective. Annals of periodontology, 2001, 6(1):99112.

20. Jansson $\mathrm{H}$ et al. Type 2 diabetes and risk for periodontal disease: a role for dental health awareness. Journal of clinical periodontology, 2006, 33:408-14.

21. Miralles $L$ et al. Dental caries in type 1 diabetics: influence of systemic factors

المجلة الصحية لشرق المتوسط، منظمة الصحة العالمية، المجلد الخامس عشر، العلدد ع، 9 . ب 
of the disease upon the development of dental caries. Medicina oral, patologia oral y cirugia bucal, 2006, 11:E256-60.

22. Wittebole $X$ et al. Expression of tumour necrosis factor receptor and Toll-like receptor 2 and 4 on peripheral blood leucocytes of human volunteers after endotoxin challenge: a comparison of flow cytometric light scatter and immunofluorescence gating. Clinical and experimental immunology, 2005, 141:99-106.

23. Oliver RC, Tervonen T. Periodontitis and tooth loss: comparing diabetics with the general population. Journal of the American Dental Association, 1993, 124(12):71-6.

24. Stöllberger C, Finsterer J. Role of infectious and immune factors in coronary and cerebrovascular arteriosclerosis. Clinical and diagnostic laboratory immunology, 2002, 9(2):207-15.

25. Buhlin $\mathrm{K}$ et al. Oral health and cardiovascular disease in Sweden. Results of a national questionnaire survey. Journal of clinical periodontology, 2002, 29:254-9.

26. Persson RE et al. Assessment of periodontal conditions and systemic disease in older subjects. II. Focus on cardiovascular diseases Journal of clinical periodontology, 2002, 29:803-10.

27. Lopez R et al. Coronary heart disease and periodontitis: a case control study in Chilean adults. Journal of clinical periodontology 2002, 29:468-73.

28. Persson GR et al. Chronic periodontitis, a significant relationship with acute myocardial infarction. European heart journal, 2003, 24:2108-15.

29. Tuominen $\mathrm{R}$ et al. Oral health indicators poorly predict coronary heart disease deaths. Journal of dental research, 2003, 82(9):713-8.

30. Montebugnoli $L$ et al. Poor oral health is associated with coronary heart disease and elevated systemic inflammatory and haemostatic factors. Journal of clinical periodontology, 2004, 31:25-9.

31. Glurich I et al. Systemic inflammation in cardiovascular and periodontal disease: comparative study. Clinical and diagnostic laboratory immunology, 2002, 9(2):425-32.

32. Noack B et al. Periodontal infections contribute to elevated systemic C-reactive protein level Periodontology, 2001, 72(9):1221-7.

33. Wang TJ et al. C-reactive protein is associated with subclinical epicardial coronary calcification in men and women: the Framingham Heart Study. Circulation, 2002, 106:1189-91.

34. Iwamoto $Y$ et al. Antimicrobial periodontal treatment decreases serum C-reactive protein, tumor necrosis factor-alpha, but not adiponectin levels in patients with chronic periodontitis. Journal of periodontology, 2003, 74(8):1231-6.

35. Hasegawa T, Negishi T, Deguchi M. WBC count, atherosclerosis and coronary risk factors. Journal of atherosclerosis and thrombosis, 2002, 9(5):219-23.

36. Gorska R et al. Relationship between clinical parameters and cytokine profiles in inflamed gingival tissue and serum samples from patients with chronic periodontitis. Journal of clinical periodontology, 2003, 30:1046-52.

37. Buhlin $\mathrm{K}$ et al. Risk factors for cardiovascular disease in patients with periodontitis. European heart journal, 2003, 24:2099-107.

38. D'Aiuto F et al. Short-term effects of intensive periodontal therapy on serum inflammatory markers and cholesterol. Journal of dental research, 2005, 84(3):269-73.

39. Yamazaki $\mathrm{K}$ et al. Effect of periodontal treatment on the C-reactive protein and pro-inflammatory cytokine levels Japanese periodontitis patient. Journal of periodontal research, 2005, 40:53-8. 
40. De Maat MP et al. Association of plasma fibrinogen levels with coronary artery disease, smoking and inflammatory markers. Atherosclerosis, 1996, 121(2):185-91.

41. Mattila $\mathrm{K}$ et al. Effect of treating periodontitis on C-reactive protein levels: a pilot study. BMC infectious diseases, 2002 $2: 30$

42. Garcia RI, Nunn ME, Vokonas PS. Epidemiologic associations between periodontal disease and chronic obstructive pulmonary disease. Annals of periodontology, 2001, 6(1):71-7.

43. Terpenning MS. The relationship between infections and chronic respiratory diseases: an overview. Annals of periodontology, 2001, 6(1):66-70.

44. Scannapieco FA, Bush RB, Paju S. Associations between periodontal disease and risk for nosocomial bacterial pneumonia and chronic obstructive pulmonary disease: a systematic review. Annals of periodontology, 2003, 8(1):54-69.

45. Wactawski-Wende J. Periodontal disease and osteoporosis: association and mechanism. Annals of periodontology, 2001 6(1):197-20.

46. Dervis E. Oral implications of osteoporosis. Oral surgery, oral medicine, oral pathology, oral radiology, and endodontics, 2005, 100(3):349-56.

47. Yaşar $F$, Akgünlü $F$. The differences in panoramic mandibular indices and fractal dimension between patients with and without spinal osteoporosis. Dentomaxillofacial radiology, 2006, 35(1):1-9.

48. Bollen AM et al. Number of teeth and residual alveolar ridge height in subjects with a history of self-reported osteoporotic fractures. Osteoporosis international, 2004, 15(12):970-4.

49. Klemetti $\mathrm{E}$ et al. Mineral status of skeleton and advanced periodontal disease. Journal of linical periodontology, 1994, 21(3):184-8.
50. Famili $P$ et al. Longitudinal study of periodontal disease and edentulism with rates of bone loss in older women. Journal of periodontology, 2005, 76(1):11-5.

51. Taguchi A et al. Oral signs as indicators of possible osteoporosis in elderly women. Oral surgery, oral medicine, oral pathology, oral radiology, and endodontics, 1995, 80(5):612-6.

52. Taguchi A et al. Tooth loss and mandibular osteopenia. Oral surgery, oral medicine, oral pathology, oral radiology, and endodontics, 1995, 79(1):127-32.

53. Proctor $\mathrm{R}$ et al. Oral and dental aspects of chronic renal failure. Journal of dental research, 2005, 84(3):199-208.

54. Al-Nowaiser A et al. Oral health in children with chronic renal failure. Pediatric nephrology (Berlin, Germany), 2003, 18(1):39-45.

55. Gavalda C et al. Renal hemodialysis patients: oral, salivary, dental and periodontal findings in 105 adult cases. Oral diseases, 1999, 5(4):299-302.

56. Lucas VS, Roberts GJ. Oro-dental health in children with chronic renal failure and after renal transplantation: a clinical review. Pediatric nephrology (Berlin, Germany), 2005, 20(10):1388-94.

57. Bayraktar $\mathrm{G}$ et al. Evaluation of salivary parameters and dental status in adult hemodialysis patients. Clinical nephrology, 2004, 62(5):380-3.

58. Epstein SR, Mandel I, Scopp IW. Salivary composition and calculus formation in patients undergoing hemodialysis. Journal of periodontology, 1980, 51(6):336-8.

59. Bots CP et al. The oral health status of dentate patients with chronic renal failure undergoing dialysis therapy. Oral diseases, 2006, 12(2):176-80.

60. Kho HS et al. Oral manifestations and salivary flow rate, $\mathrm{pH}$, and buffer capacity in patients with end-stage renal disease un-

المجلة الصحية لشرق المتوسط، منظمة الصحة العالمية، المجلد الخامس عشر، العدد ع، 9 . ب 
dergoing hemodialysis. Oral surgery, oral medicine, oral pathology, oral radiology, and endodontics, 1999, 88(3):316-9.

61. Bokhari SAH, Khan AA. The relationship of periodontal disease to cardiovascular diseases: review of literature. Journal of the Pakistan Medical Association, 2006, 56(4):177-81.

62. Scannapieco FA, Ho AW. Potential associations between chronic respiratory disease and periodontal disease: analysis of National Health and Nutrition Examination Survey III. Journal of periodontology, 2001, 72(1):50-6.

63. Mohammad AR, Jones JD. Osteoporosis and periodontal disease: a review. Journal of the California Dental Association, 1994, 22(3):69-75.

64. Yoshihara A et al. A longitudinal study of the relationship between periodontal disease and bone mineral density in community-dwelling older adults. Journal of clinical periodontology, 2004, 31(8):680-4.

65. Southerland JH, Taylor GW, Offenbacher S. Diabetes and periodontal infection: making the connection. Clinical diabetes, 2005, 23(4):171-8.

66. Chen LP et al. Does periodontitis reflect inflammation and malnutrition status in hemodialysis patients? American journal of kidney diseases, 2006, 47(5):815-22.

67. Murray CJ, Lopez AD. Alternative projections of mortality and disability by cause 1990-2020: Global Burden of Disease Study. Lancet, 1997, 349:1498-504.

68. Fuster V, Voute J. MGDS: chronic diseases are not on the agenda. Lancet, 2005, 366:1512-4.
69. Geerts SO et al. Systemic release of endotoxins induced by gentle mastication: association with periodontitis severity. Journal of periodontology, 2002, 73(1):73-8.

70. Paquette DW. The concept of "risk" and the emerging discipline of periodontal medicine. Journal of contemporary dental practice, 1999, 1(1):1-18.

71. Lown B, Banerjee A. The developing world in The New England journal of medicine. Globalization and health, 2006, $2: 3$

72. Khan MS et al. Knowledge of modifiable risk factors of heart disease among patients with acute myocardial infarction in Karachi, Pakistan: a cross-sectional study. BMC cardiovascular disorders, 2006, 6:18.

73. National action plan for prevention and control of non-communicable diseases and health promotion in Pakistan. Islamabad, Pakistan, Ministry of Health, Government of Pakistan/World Health Organization, Pakistan Office/Heartfile, 2004.

74. Bokhari SAH, Khan AA. Dental research and journalism in Eastern Mediterranean countries. Journal of the Pakistan Dental Association, 2009 [in press].

75. Bonita R et al. Surveillance of risk factors for non-communicable diseases. The WHO STEPwise approach. Summary. Geneva, World Health Organization, 2003 (WHO/NMH/CCS/01.01).

76. Ruger JP. Health and development. Lancet, 2003, 362:678. 